\title{
Cloned Interstitial Stem Cells Grow as Contiguous Patches in Hydra
}

\author{
Thomas C. G. Bosch ${ }^{1}$ and Charles N. David \\ Zoologisches Institut der Universität, Luisenstr. 14, 8000 Munich 2, Federal Remublic of Germany \\ Accepted December \%, 1989
}

\begin{abstract}
The migration of interstitial cells was analyzed during the growth of stem cell clones in vivo. The spatial distribution of cloned cells was analyzed at a time by which extensive migration of interstitial cells could have occurred. All interstitial cell clones were found to form large contıguous patches of cells. The results indicate that there is little migration of large interstitial cells in undisturbed tissue during normal growth. This finding is surprising since numerous grafting experiments have shown extensive migration of these cells. The implications of finding nonrandomly distributed stem cells are discussed. (c) 1990 Academic Press, Inc.
\end{abstract}

\section{INTRODUTTION}

The interstitial cell lineage of hydra represents a well-studied experimental system for analyzing the control of stem cell proliferation and differentiation (for review see David et al., 1987). The interstitial cell population contains multipotent stem cells which are able to differentiate into nematocytes, nerve cells, and gland cells, as well as into gametes (David and Murphy, 1977; Bosch and David, 1987). Interstitial cells are located primarily in the ectoderm of hydra where they are homogeneously distributed throughout the gastric region; very few interstitial cells are found in the hypostome and basal disc (David and Plotnick, 1980).

Interstitial cells have been shown to migrate extensively along the body column when labeled and unlabeled tissue are grafted together (Tardent and Morgenthaler, 1966; Herlands and Bode, 1974). IIeimfeld and Bode (1984a) found that a substantial fraction of the interstitial cell population is migratory and suggested that migration is important in the generation of the spatial pattern of nerve cell and nemalocyte differentiation (Heimfeld and Bode, 1984b). If the extensive migration of interstitial cells observed in grafting experiments reflects the in vivo situation in undisturbed tissue, then random mixing of interstitial cells in the body column would be the consequence. Since there is continuous cell proliferation in hydra and displacement of the tissue from the body column into buds (Campbell, 1967; Campbell and David, 1974), this would suggest that buds get a random mixture of interstitial cells from the parental polyp.

$\Lambda$ quite different hypothesis arises from studies of sex determination in hydra polyps. During the growth

\footnotetext{
${ }^{1}$ To whom correspondence should be addressed.
}

of mass cultures of hydra, buds occasionally arise which have the sex opposite from that of parent polyps (Bosch, personal observation; Bosch and David, 1986). Since there are male and female interstitial cells in hydra (Bosch and David, 1986) and since interstitial cells determine the sex of hydra polyps (Littlefield, 1984; Campbell, 1985) it seems likely that such sex reversal events result from the nonrandom distribution of male or female interstitial cells to developing buds. This implies that interstitial cells grow as clones and thus are nonrandomly distributed in tissue.

In the present study we analyzed the spatial distribution of clones of interstitial cells growing as clones in vivo. The clonally derived cells were always found in large contiguous patches. Thus, the extent of interstitial cell migration is limited. The implications of these findings for sex determination are discussed.

MATERIALS AND METHODS

\section{Strains and Culture Conditions}

Two strains of Hydra magnipapillata were used. Strain ms-1 (Sugiyama and Fujisawa, 1977) was used as the interstitial cell donor; strain sf-1, which has temperature-sensitive interstitial cells (Marcum et $a l$, 1980), was used as the host. Animals were cultured as described previously (Bosch and David, 1987). Culture of strain sf- 1 at $24^{\circ} \mathrm{C}$ for 3 days eliminated all interstitial cells (see also Marcum et al., 1980).

\section{Preparation of Stem Cell Clones}

Interstitial stem cells were cloned using the procedure described by Bosch and David (1987). Small numbers of dissociated ms-1 cells were mixed with large 
numbers of dissociated sf-1 cells. Aggregates were made by centrifugation and the resulting pellets were allowed to regenerate. Aggregates generally regenerated as single polyps. The number of clone-forming units per aggregate was determined by applying Poisson statistics and only aggregates from classes containing single clones $[P(1) \leqslant 0.22 ; P(\geqslant 2) \leqslant 0.037]$ were analyzed.

\section{Visualization of Interstitial Cell Clones within Aggregates}

To visualize ms-1 interstitial cell clones, the host sf- 1 interstitial cells were eliminated by treatment of aggregates at the nonpermissive temperature $\left(24^{\circ} \mathrm{C}\right)$ for 3 days. Clones of ms-1 cells were then visualized by staining alcohol-fixed aggregates with $0.05 \%$ toluidine blue (David and Murphy, 1977). Interstitial cells can be recognized as they stain much more darkly than the epithelial tissue.

\section{RESULTS AND DISCUSSION}

Clones of ms-1 cells were prepared in sf- 1 tissue and cultured for 16 days at the permissive temperature of $18^{\circ} \mathrm{C}$. Thereafter they were cultured for 3 days at $24^{\circ} \mathrm{C}$ to eliminate sf- 1 host cells. On Day 19 the ms-1 clones were found to contain an average of 214 single or paired interstitial cells (Bosch and David, 1987). Thus, under these conditions the ms-1 interstitial cells proliferate with an approximate doubling time of 4 days, which is similar to the doubling time of interstitial cells in normal hydra.

To visualize the spatial distribution of the cloned interstitial cells, 27 aggregates were fixed on Day 19 and stained with toluidine blue. Figure 1 shows camera lu cida drawings of nine representative interstitial cell clones. All clones were found to occur as contiguous patches of large interstitial cells in the ectodermal epithelium. The clones were elongated along the apicalbasal axis of the polyps (see also Fig. 3 in Bosch and David, 1987).

Our experimental conditions permit normal growth of hydra tissue. Since clones grew under these conditions as contiguous patches of cells, we conclude that interstitial cells do not migrate extensively in undisturbed tissue. Consistent with this conclusion are previous observations made in hydroxyurea-treated polyps of Hydra attenuata (Heimfeld, 1985) and female polyps of Hydra oligactis (Littlefield, personal communication), which also show hydroxyurea-resistent interstitial cells growing in contiguous patches. Why the clones always are found elongated along the apical-basal axis remains unknown. The shape might be due to axially

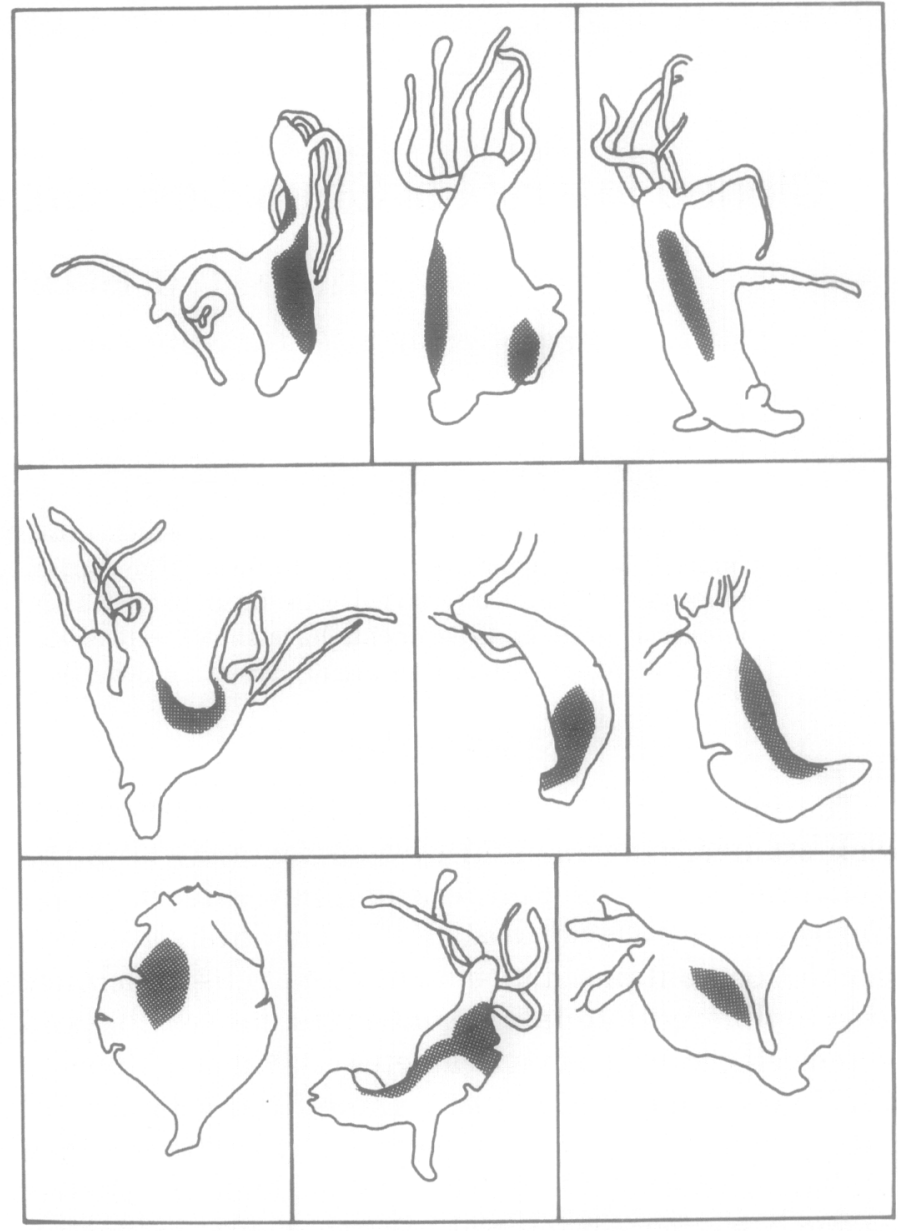

FIg. 1. Spatial distribution of interstitial stem cell clones in 19day-old aggregates (Camera lucida drawings of alcohol-fixed and Toluidine blue-stained aggregates).

oriented mitotic spindles. However, it is also possible that some limited migratory activity of the interstitial cells contributes to the elongated shape.

The observation of contiguous patches of large interstitial cells was unexpected since numerous grafting experiments have shown that interstitial cells are able to migrate in hydra tissue. In particular axial grafting experiments have shown that 200 to 400 interstitial cells migrate from bottom to top halves of grafted animals within 1 day (Heimfeld and Bode, 1984a). By comparison, in our cloning experiments, even after long periods of growth, no migration was observed.

Is there any explanation for this obvious discrepancy? The most obvious difference between the two types of experiments is the grafting procedure itself. Indeed all previous experiments demonstrating extensive migration of interstitial cells (Tardent and Morgenthaler, 1966; Herlands and Bode, 1974; Heimfeld and Bode, 1984a) involved grafting of marked and unmarked 
tissue. By contrast, our experimental conditions involve no manipulation of the tissue. Thus the simplest explanation for the different observations is that wounding of the tissue associated with the grafting procedure induces interstitial cell migration. In support of this hypothesis, we present data in the following paper (Fujisawa et al., 1990) indicating that interstitial cell motility is markedly stimulated by grafting procedures.

The growth of stem cell clones as contiguous patches of cells provides a simple mechanism for the differential distribution of stem cells to developing buds. A striking example of such a nonuniform distribution of interstitial cells in the budding region can be found in Fig. 3 in Heimfeld (1985). Whereas the gastric region of the depicted polyp shows a single contiguous patch of interstitial cells, the evaginating bud does not contain any of these cells.

One consequence of the localization of cloned interstitial cells in patches is that asexual proliferation by budding can lead to sex reversal in polyps. Male polyps contain both male and female stem cells (Bosch and David, 1986). These polyps are phenotypically male because male stem cells repress differentiation of female stem cells (Littlefield, 1985). Since stem cells grow in clonal patches, such male polyps ean give rise to female polyps by producing buds containing female cells only (Bosch and David, 1986). The occasional observation of female polyps in mass cultures of male strains of $H$. magnipapillata (Bosch, personal observation; Sugiyama, personal communication) appears to be the consequence of such a budding event.

We thank Dr. T. Sugiyama, Mishima, for supplying the $H$. magnipupillatu strains and Drs. Hans Bode, Thomas Holstein, and Lynne Littlefield for critical reading an early version of the manuscript. This study was supported by the Deutsche Forschungsgemeinschaft (Da $163 / 2$ )

\section{REFERENCES}

Bosch, T. C. G., and DAvin, C. N. (1986). Male and female stem cells and sex reversal in Hydre polyps. Proc. Natl. Acad. Sci. USA 83 , 9478-9482.

Bosc:H, T. C. G., and DAvin, C. N. (1987). Stem cells of Hydra magnipapilata can differentiate into somatic cells and germ line cells. Dev Biol. 121, 182-191.

Brifn, P., and Reniers-Dfookn, M. (1951). La gametogenese et l'in- tersexualité chez Hydra attenuata (Pall.). Ann. Soc. R. Zool. Belg. 82, $285-380$.

Campbell, R. D. (1967). Tissue dynamies of steady state growth in Hydra littoralis. II. Patterns of tissue movement. J. Morphol. 121, $19-28$.

CAMPBEll, R. D. (1985). Sex determination in Hydra: Roles of germ cells (interstitial cells) and somatic cells. J. Exp. Zool. 234, 451-458.

CAmpbell, R. D., and David, C. N. (1974). Cell cycle kineties and development of Hydra attenuata. II. Interstitial cells. J. Cell Sci. 16, $349-358$.

David, C. N., Bosch, T. C. G., Hobmeyer, B., Holstein, T., and SchimidT, T. (1987). Interstitial stem cells in hydra. In "Genetic Regulation of Development" (W. F. Loomis, Ed.), pp. 389-408. A. R. Liss, New York

DAVID, C. N., and MurPHY, S. (1977). Characterization of interstitial stem cells in hydra by cloning. Dev. Biol. 58, 373-383.

DAvin, C. N., and PLotNICK, I. (1980). Distribution of interstitial stem cells in Hydra. Dev. Biol. 76, 175-184.

Fujisawa, T., David, C. N., and Bosch, T. C. G. (1990). Transplantation stimulates interstitial cell migration in hydra. Den. Biol. 138, 509-512.

HeimfEid, S. (1985). Growth regulation of the interstitial cell population in hydra. II. A new mechanism for the homeostatic recovery of reduced interstitial cell populations. Dev. Biol. 111, 499-509.

Heimfeid, S., and BoDE, H. R. (1984a). Interstitial cell migration in Hydra attenuata. I. Quantitative description of cell movements. Dex: Biol. 105, 1-9.

HeImFELD, S., and Bonf, H. R. (1984b). Interstitial cell migration in Hydra attenuata. I. Selective migration of nerve cell precursors as the basis for position-dependent nerve cell differentiation. Dev. Biol. 105, 10-17.

Herlands, R. L., and Bode, H. R. (1974). Oriented migration of interstitial cells and nematocytes in Hydra attenuata. Wilhelm Roux' Arch. Entwicklungsmech. Org. 176, 67-88.

LitTl.FFini, C. L. (1984). The interstitial cells control the sexual phenotype of heterosexual chimeras of hydra. Dev. Biol. 102, $426-432$.

LITTLEFILI,1), C. L. (1985). Germ cells in Hydra oligactis males. I. Isolation of a subpopulation of interstitial cells that is developmentally restricted to sperm production. Dev. Biol. 112, 185-193.

Marcum, B. A., Sugryama, T., and Fujisawa, T. (1980). A mutant strain (sf-1) containing temperature-sensitive interstitial cells. In "Developmental and Cellular Biology of Coelenterates" (P. Tardent and R. Tardent, Eds.), pp. 429-434. Elsevier/North-Holland, Amsterdam.

Sugiyama, T., and Fujisawa, T. (1977). Genetic analysis of developmental mechanisms in hydra. I. Sexual reproduction of Hydro magnipapillata and isolation of mutants. Dev. Growth Differ. 19, $187-200$

TARinenT, P. (1966). Zur Sexualbiologie von Hydra attenuata. Rev Suisse Zool. 73, 357-381.

TARDent, P., and Morgenthaler, U. (1966). Autoradiographische Untersuchungen zum Problem der Zellwanderungen bei Hydra attemuta (Pall.). Rev Suisse Zool 79, 649-674 